\title{
PPM Aneka Makanan Tradisional Nasi Pecel Rasa Keju (Pecel Keju Mbok Moe) di Kelurahan Kandangan Kecamatan Benowo Surabaya
}

\author{
C. Sri Hartati, Fransisca Romana Sunarmi, Woro Utari \\ ${ }^{1}$ Universitas Wijaya Putra \\ ${ }^{2}$ STKIP BIIM \\ ${ }^{3}$ Universitas Wijaya Putra
}

srihartati@uwp.ac.id, fransiscasunarmi@yaoo.co.id, woro.utari@yahoo.co.id

\begin{abstract}
Abstrak
Tujuan dari Program Pengabdian Masyarakat/PPM Pecel Keju Mbok Moe adalah Mengembangkan usaha Pecel Keju Mbok Moe menjadi usaha yang mandiri secara ekonomi, meningkatkan produksi dan mutu dari Pecel Keju Mbok Moe dan Peningkatan pendapatan usaha makanan tradisional Nasi Pecel Rasa Keju. Pelaksanaan PPM ini bertempat di Pecel Keju Mbok Moe di ruko jl. Wisma Tengger no.19 Desa Kandangan Kecamatan Benowo Surabaya.

Metode yang dilaksanakan : (1)Pelatihan tentang manajemen keuangan dan pemasaran, (2)Pendampingan packaging produk. (3) Mengadakan pendampingan dan pemantauan pemasaran selama 3 bulan (4),Mencarikan pemasok bahan baku pecel yang enak dan murah.

Hasil Kegiatan PPM Pecel Keju Mbok Moe : (1) Adanya peningkatan produk Pecel Keju dengan besarnya permintaan konsumen dengan rata-rata per hari 350-400 bungkus dengan harga normal per bungkus sebesar Rp. 7.500.-sampai dengan Rp.10.000.-, (2) Mitra sudah mulai melaksanakan pencatatan aliran kas penerimaan dan Penjualan, (3) Adanya Peningkatan Mutu Produk Pecel Keju dengan kemasan yang lebih bersih/steril. (4), Pasokan bahan baku makanan tradisional Pecel Keju sudah teratasi dengan dipertemukannya pemasok bahan baku. (5). Adanya peningkatan pendapatan mitra.

Hasil Luaran dari PPM ini adalah : (1). Peningkatan daya saing produk (kuantitas, kualitas, diversifikasi produk makanan tradisional, (2) Peningkatan penerapatan Ipteks bagi mitra, (3). Jurnal Nasional Pengabdian Masyarakat.
\end{abstract}

Kata Kunci : Pecel Keju MbokMoe, Packaging, Manajemen

\section{PENDAHULUAN}

Pecel keju adalah varian baru dari produk pecel yang tidak seperti biasanya. Sementara anggapan masyarakat apakah pecel diberi keju itu enak, bagaimanakah rasanya? Membuat penasaran yang mendengar berita ini lalu Daniel Waskito Jati yang membuat inovasi ini.

Pecel ini dinamakan pecel keju karena sambal pecelnya dicampur dengan keju sehingga rasa pecel itu lebih gurih, untuk sayurnya sama seperti pecel yang biasa kita jumpai, lauk pauk dari pecel itu disediakan peyek, bali telor dan tahu, 
tempe dan tahu bacem, rempelo ati goreng dan telor dadar. Pecel keju tidak hanya dipasarkan bersamaan dengan nasi dan lauk pauk tetapi disini akan dikembangkan dengan menjual pecel keju dengan kemasan/packing lebih bagus dengan menggunakan brand/logo.

Sehingga dengan harapan dapat menambah income dan produknya dapat berkembang. Tujuan dari Program Pengabdian Masyarakat/PPM Pecel Keju Mbok Moe adalah Mengembangkan usaha Pecel Keju Mbok Moe menjadi usaha yang mandiri secara ekonomi, meningkatkan produksi dan mutu dari Pecel Keju Mbok Moe dan Peningkatan pendapatan usaha makanan tradisional Nasi Pecel Rasa Keju.

\section{METODE}

Agar lebih jelas dalam pelaksanaan pelatihan dan pendampingan perlu dibuatnya langkah-langkah kegiatan agar dalam pelaksanaan PPM nanti tepat pada sasaran, adapun langkah-langkah tersebut sebagai berikut : (1) Pelatihan tentang manajemen keuangan dan pemasaran. (2) Cara paking produk dengan mendatangkan bapak Faisol Humaidi, SP, MM dari Universitas Wijaya Putra yang sudah pengalaman dalam PPM produk pemasaran. (3) Mengadakan pendampingan dan pemantauan pemasaran selama 3 bulan

Mencarikan pemasok bahan baku yang enak dan murah.

\section{HASIL DAN PEMBAHASAN}

\section{Hasil yang dicapai}

Hasil Kegiatan PPM Pecel Keju Mbok Moe : (1) Adanya peningkatan produk Pecel Keju dengan besarnya permintaan konsumen dengan rata-rata per hari 350-400 bungkus dengan harga normal per bungkus sebesar Rp. 7.500.-sampai dengan Rp.10.000.-, (2) Mitra sudah mulai melaksanakan pencatatan aliran kas penerimaan dan Penjualan, (3) Adanya Peningkatan Mutu Produk Pecel Keju dengan kemasan yang lebih bersih/steril. (4), Pasokan bahan baku makanan tradisional Pecel Keju sudah teratasi dengan dipertemukannya pemasok bahan baku. (5). Adanya peningkatan pendapatan mitra.

\section{Hasil Luaran}

Hasil Luaran dari PPM ini adalah : (1). Peningkatan daya saing produk (kuantitas, kualitas, diversifikasi produk makanan tradisional,

(2) Peningkatan penerapatan Ipteks bagi mitra, (3). Jurnal Nasional Pengabdian Masyarakat.

\section{Peningkatan daya saing produk}
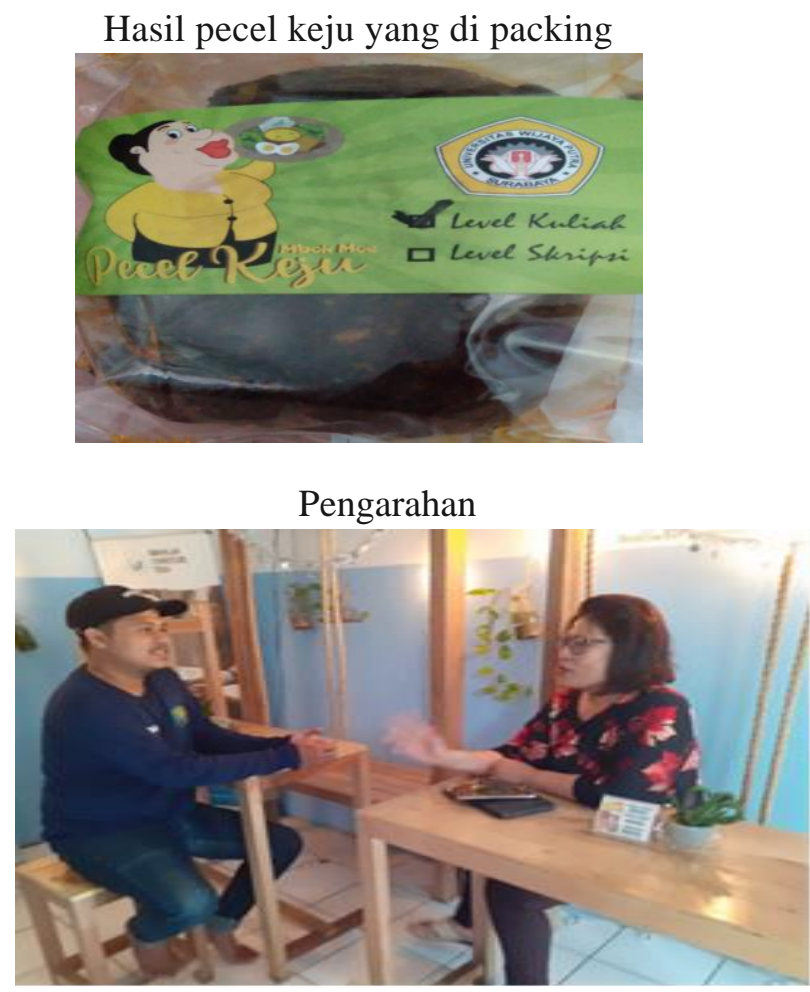

\section{Peningkatan penerapatan Ipteks bagi mitra}

Penawaran produk di akun media online (istagram)

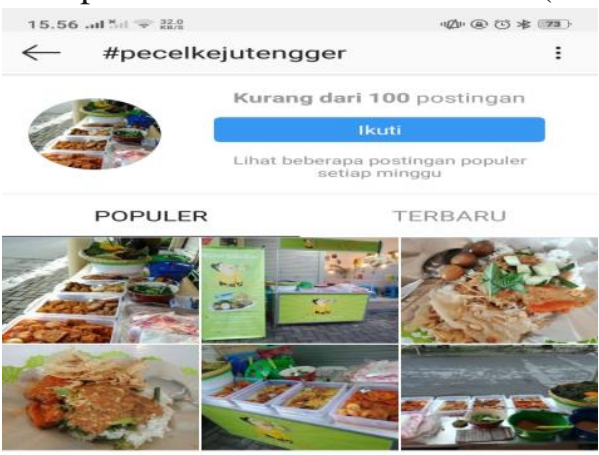

Ekonomi, Sosial, dan Budaya 


\section{KESIMPULAN}

Berdasarkan program kegiatan PPM yang sudah dilaksanakan dan hasil yang capai maka dapat disimpulan sebagai berikut: (1) Dengan diperbaikinya cara penyajian pemasaran di warung sehingga dapat meningkatkan daya saing di masyarakat sekitar. (2) Mitra sudah memiliki akun di istagram. (3) Mitra sudah bisa melakukan penyusunan transaksi harian dengan mendasarkan manajemen yang disarankan. (4) Mitra sudah mengembangkan produk pecel keju dengan packingging yang lebih menarik (5) Omset penjualan mitra mengalami kenaikan.

\section{UCAPAN TERIMAKASIH}

Terimakasih kepada Universitas Wijaya Putra yang telah memberikan kontribusi dalam pelaksanaan kegiatan CSR th 2019 .

\section{REFERENSI}

Alma, Buchari. 2014. Manajemen Pemasaran dan Pemasaran Jasa. Bandung : Alfabeta.
Alma, Buchari. 2016. Mnajemen Pemasaran dan Pemasaran jasa. Bandung : Alfabeta.

Basu, S,. \& Irawan, H. 2012. Manajemen Pemasaran Modern Edisi ke-2. Yogyakarta : Liberty Offset.

Kirom, bahrul. 2014. Mengukur Kinerja Pelayan dan Kepuasan konsumen : Service Perfomance and Custome Satisfaction Measurement. Tanggerang : Pustaka Reka Cipta.

Kurtz, D.L. 2011. Principles of Contemporary Marketing 14th Edition. Stamford : South Western Education Publishing.

Rangkuti, F. 2012. The Power of Brand. Jakarta : PT. Gramedia Pustka Utama

Rangkuti, F. 2016. Teknik Membedah Kasus Bisnis Analisis SWOT Cara Perhitungan Bobot, Rating, dan OCAI. Jakarta : PT. Gramedia Pustaka Utama

Tjiptono, Fandy. 2014. Pemasaran Jasa. Yogyakarta : Penerbit Andi.

Tjiptono, Fandy. 2015. Strategi Pemasaran. Yogyakarta : Penerbit Andi 